\title{
KEEFEKTIFAN METODE KLARIFIKASI NILAI DALAM MENINGKATKAN KARAKTER SISWA PADA MATA PELAJARAN PKN
}

\author{
Ari Wibowo \\ Universitas PGRI Yogyakarta \\ e-mail: ari3.pkn69@yahoo.com, Hp.085740918181
}

\begin{abstract}
Abstrak
Tujuan dari penelitian ini adalah untuk mengetahui perbedaan keefektifan metode klarifikasi nilai dan metode konvensional terhadap karakter yang meliputi kreativitas, tanggung jawab, kemandirian, dan empati. Penelitian ini adalah quasi eksperimen untuk membandingkan keefektifan metode klarifikasi nilai dan metode konvensional dalam pembelajaran PKn. Populasi penelitian ini adalah siswa kelas XI SMA Laboratorium School Universitas Kristen Satya Wacana Salatiga. Teknik analisis data hasil belajar digunakan independent sample t-test, sedangkan untuk karakter digunakan MANOVA (Multivariate Analysis of Variance) pada taraf signifikansi 0,05. Hasil penelitian menyimpulkan Terdapat perbedaan secara signifikan terhadap karakter siswa yang meliputi tanggung jawab, kemandirian dan empati, sedangkan karakter kreativitas tidak terdapat perbedaan yang signifikan. Dibuktikan dengan uji MANOVA bahwa $F=2,400, \rho=0,127$ untuk kreativitas, untuk tanggung jawab adalah 5,77 dengan $\rho=0,019$, sedangkan kemandirian $\mathrm{F}=17,07$ dengan $\rho=0,000$, dan untuk empati $\mathrm{F}=12,82$ dengan $\rho=0,001$. Dari perbandingan tersebut dapat disimpulkan bahwa kenaikan skor hasil belajar PKn dan karakter siswa yang meliputi tanggung jawab, kemandirian dan empati pada kelas eksperimen lebih tinggi dari pada kelas kontrol. Dengan kata lain bahwa penggunaan metode klarifikasi nilai lebih efektif dibandingkan dengan metode konvensional.
\end{abstract}

Kata kunci: metode klarifikasi nilai, hasil belajar, kreativitas, tanggung jawab, kemandirian, empati. 


\begin{abstract}
The aims of this research were to find out the difference of effectiveness between value clarification method and conventional method towards students characters in terms of creativity, responsibility, independency, and empathy. This research was a quasi-experiment research study to compare value clarification method to conventional method in civics class. The population in research was grade $11^{\text {th }}$ students in Satya Wacana Christian High School Salatiga. The data of students achievement was analyzed by using independent sample t-test, while students characters was analyzed by MANOVA (Multivariate Analysis of Variance) in the significance level of 0,05. The result of the result shows that there are significant differences towards student characters which include responsibility, independency, and empathy, where as there is no significant difference related to creativity. It is proven by MANOVA test which results in $F=2,400, \rho=0,127$ for creativity, $F=5,77$ and $\rho=$ 0,019 for responsibility, $F=17,07$ and $\rho=0,000$ for independency, and $F=12,82$ and $\rho=0,001$ for empathy. From the comparison, it can be concluded that the score of student academic result in civics class and students characters in the experiment group is higher than control group. In other words, the use of value clarification method was more effective than conventional method.
\end{abstract}

Keywords: value clarification method, score of students' academic, creativity, responsibility, independency, and empathy

\title{
Pendahuluan
}

Beberapa tahun belakangan ini, Indonesia dihadapkan pada krisis multi dimensi yang menyinggung persoalan mendasar bagi kehidupan manusia. Mulai dari aspek ekonomi, sosial, moral, budaya dan utamanya adalah krisis akhlak. Krisis pada aspek sosial khususnya sudah sampai pada bentuk yang memprihatinkan. Berbagai bentuk penyimpangan perilaku sosial diperlihatkan tidak hanya oleh para siswa tetapi juga oleh mahasiswa, bahkan orang dewasa.

Masalah tersebut tidak terlepas dari proses pendidikan yang terjadi dewasa ini, mengingat bahwa pendidikan adalah pilar utama berdirinya sebuah negara. Melalui pendidikan akan 
tercetak warga masyarakat sesuai dengan karakter bangsa. Baik buruknya suatu negara di masa kini tidak terlepas dari pola pendidikan yang diselenggarakan di masa lampau. Kenyataan ini terjadi pada setiap mata pelajaran, tidak terkecuali mata pelajaran Pendidikan Kewarganegaraan. Kegagalan pendidikan terkait dengan pembentukan karakter bangsa tersebut, tidak terlepas dari kegagalan mata pelajaran PKn dalam usaha menginternalisasi nilai-nilai Pancasila. Praktik pendidikan yang semestinya memperkuat aspek karakter atau nilai-nilai kebaikan sejauh ini hanya mampu menghasilkan berbagai sikap dan perilaku manusia yang nyata malah bertolak belakang dengan apa yang diajarkan.

Buyamin Muftah (2008: 143) mengemukakan bahwa dalam mengajarkan nilai-nilai Pancasila, PKn perlu secara terintegrasi menggunakan pendekatan pendidikan nilai secara langsung, yang didasari oleh perspektif sosialisasi, dan pendekatan pendidikan nilai secara tidak langsung. Pembelajaran PKn pun hendaknya memiliki kekuatan (powerful), yakni pembelajaran PKn yang bermuatan nilai, bermakna, aktif, terpadu, mengundang kemampuan berfikir kritis, demokratis, menyenangkan, efektif, efisien, kreatif, melalui belajar dengan bekerja sama (cooperative learning), dan mengundang aktivitas sosial. Dengan menggunakan kedua pendekatan itu, secara terintegrasi dan didukung oleh suasana pembelajaran yang memiliki kekuatan seperti di atas, diharapkan para siswa dapat menerima dan mengamalkan nilainilai Pancasila dan nasionalisme dengan penuh nalar dan keyakinan. Upaya pembinaan nilai di atas sejalan dengan model pendidikan nilai.

Metode ini memberikan penekanan pada nilai-nilai yang sesungguhnya dimiliki seseorang. Klarifikasi nilai adalah metode yang membantu siswa untuk memahami dan memilih nilai yang 
mereka yakini. Klarifikasi nilai merupakan salah satu metode yang berupaya menumbuhkan kecerdasan intelektual anak didik agar mampu melahirkan suatu keputusan moral yang terbaik dan penuh rasa tanggung jawab. Metode ini, mengajarkan siswa untuk mengatasi masalah, sekalipun dalam situasi nilai moral yang sangat dilematis dan problematik. Menurut Superka (Zaim Elmubarok, 2009:70) tujuan nilai menurut pendekatan ini ada tiga, pertama membantu siswa menyadari dan mengidentifikasi nilai-nilai mereka sendiri serta nilai-nilai orang lain. Kedua, membantu siswa supaya mereka mampu berkomunikasi secara terbuka dan jujur dengan orang lain, berhubungan dengan nilai-nilainya sendiri. Ketiga, supaya mereka mampu menggunakan secara bersama-sama kemampuan berpikir rasional dan kesadaran emosional untuk memahami perasaan, nilai-nilai, dan pola tingkah laku mereka sendiri .

Berdasarkan pembatasan masalah di atas, rumusan masalahnya adalah "Apakah ada perbedaan karakter antara siswa yang belajar dengan menggunakan metode Klarifikasi Nilai dengan siswa yang menggunakan metode konvensional di SMA Laboratorium School Universitas Kristen Satya Wacana Salatiga?

\section{Pengertian Karakter}

Pengertian pendidikan karakter seperti yang diutarakan oleh Darmiyati Zuchdi (2012: 3) bahwa:

Secara akademis, pendidikan karakter dimaknai sebagai pendidikan nilai, pendidikan budi pekerti, pendidikan moral, pendidikan watak atau pendidikan akhlak yang tujuannya mengembangkan kemampuan peserta didik untuk memberikan keputusan baik-buruk, memelihara apa yang baik itu, dan mewujudkan kebaikan itu dalam kehidupan sehari-hari. 
Awilson (Tadkiroatun Musfiroh, 2008: 27) mendefinisikan karakter sebagai gambaran tingkah laku yang menonjolkan nilai benar salah, baik-buruk, baik secara eksplisit maupun implisit. Sedangkan Mouniter (Doni Koesoma, 2007: 90) mengajukan dua cara interpretasi. Ia melihat karakter sebagai dua hal, pertama sebagai sekumpulan kondisi yang telah diberikan begitu saja, atau telah ada begitu saja, yang lebih kurang dipaksakan dalam diri kita. Karakter yag demikian ini dianggap sebagai sesuatu yang telah ada sejak lahir (given). Kedua, karakter juga bisa dipahami sebagai tingkat kekuatan melalui sejauh mana seorang individu mampu menuasai kondisi tersebut. Karakter yang demikian ini disebutnya sebagai sebuah proses yang dikehendaki (willed).

Said Hamid Hasan, dkk dalam naskah akademik "Pengembangan Pendidikan Budaya dan Karakter Bangsa" Kementrian Pendidikan Nasional (2010: 13) merumuskan karakter adalah watak, tabiat, aqhlak atau kepribadian seseorang yang terbentuk dari hasil internaliasai berbagai kebajikan (virtues) yang diyakini dan digunakan sebagai landasan untuk cara pandang, berfikir, bersikap, dan bertindak. Kebajikan terdiri dari sejumlah nilai, moral dan norma, seperti jujur, berani bertindak, dapat dipercaya, dan hormat kepada orang lain. Interaksi seseorang dengan orang lain dapat menumbuhkan karakter individu tersebut. Lickona (1991: 53-62) menekankan pentingnya tiga komponen karakter yang baik (competents of good character) yaitu moral knowing atau pengetahuan moral, moral feeling atau perasaan moral, dan moral action atau perbuatan bermoral. Lickona (1992: 50) menyatakan bahwa:

Characrter observe contemporary philosopher Michael Novak, is a compatible mix of all those virtues identified by religious traditios, literary stories, the sages and persons of common sense down through history. 
Ari Wibowo

Berdasarkan pengertian tersebut, dapat dipahami bahwa karakter adalah percampuran yang harmonis dari semua kebajikan yang diidentifikasi oleh tradisi agama, cerita sastra, orang bijak yang merasa melewati proses sejarah.

Zubaedi (2011:17) mengemukakan bahwa pendidikan karakter merupakan upaya penanaman kecerdasan dalam berpikir, penghayatan dalam bentuk sikap, dan pengalaman dalam bentuk perilaku sesuai dengan nilai-nilai luhur yang menjadi jati dirinya. Dalam hal mengajarkan karakter Kirschenbaum (2000: 16) menyatakan:

"If we teach or tell something directly, people may remember a certain amount of it. If we demonstrate what we are teaching, they will remember even more. But if we also give them an opportunity to process that information and make personal meaning out of it, they will remember still more and retain it longer, and it will have a deeper impact on their behavior. Values education must be comprehensive to be most effective".

Dari pernyataan diatas dapat dilihat bahwa dalam mengajarkan karakter, jika kita menunjukkan apa yang kita ajarkan, mereka akan mengingat lebih banyak. Tetapi jika kita juga memberi mereka kesempatan untuk memproses informasi tersebut dan membuat makna pribadi, mereka akan mengingat lebih banyak dan mempertahankan lebih lama, dan itu akan memiliki dampak yang lebih pada perilaku mereka. Pendidikan nilai harus komprehensif untuk agar efektif. Karakter yang menjadi target dalam penelitian ini adalah kreatifitas, tanggung jawab, kemandirian, dan empati.

Pendidikan karakter yang terintegrasi meliputi dimensi penting yang dapat digambarkan dalam beberapa tindakan, maksudnya pendekatan pendidikan karakter yang terintegrasi dalam pembelajaran bahwa guru dan siswa bekerja sama dalam 
proses pembelajaran yang berorintasi pada tindakan yang lebih bermakna. Tujuan Pendidikan Nasional sebagai rumusan kualitas yang harus dimiliki setiap warga negara Indonesia, dikembangkan oleh berbagai satuan pendidikan di berbagai jenjang dan jalur. Tujuan pendidikan nasional memuat berbagai nilai kemanusiaan yang harus dimiliki warga negara Indonesia.

\section{Karakteristik PKn}

Samsuri (2011:18) menyatakan bahwa pendidikan kewarganegaraan merupakan upaya pendagogis pembentukan watak warga negara yang baik, yakni memiliki penalaran moral untuk bertindak atau tidak bertindak dalam urusan publik maupun privat. Perlu dijelaskan bahwa dalam pembelajaran PKn yang menjadi target yaitu terintegrasinya ketiga aspek pendidikan yaitu aspek pemahaman (teoritik), sikap dan tingkah laku (praktik). Atas pemahaman yang benar diharapkan suatu materi pembelajaran (nilai-nilai) maka diharapkan diwujudkan dalam sikap dan perilaku sesuai warga negara yang baik atau berbudi pekerti luhur. Sikap sebenarnya merupakan hasil belajar yang merupakan kecenderungan bertindak atas pemahaman suatu objek tertentu yang berada dalam hati seseorang. Sedangkan perilaku adalah suatu tindakan atau perbuatan sebagai cerminan dari sikapnya. Sikap merupakan hasil belajar yang berupa kecenderungan bertindak terhadap sesuatu objek sosial yang terbentuk berdasarkan pengetahuan. Melalui sikap akan menumbuhkan perilaku-perilaku yang sesuai dengan nilai-nilai atau bahkan bertentangan dengan nilai-nilai yang dipelajari.

Dalam penjelasan pasal 37 UUSPN No.20 tahun 2003 ditegaskan bahwa pendidikan kewarganegaraan dimaksudkan untuk membentuk peserta didik menjadi manusia yang memiliki rasa kebangsaan dan cinta tanah air. PKn yang diselenggarakan 
dengan baik akan menumbuhkan sikap mental yang cerdas, penuh rasa tanggung jawab pada peserta didik dengan perilaku yang: (1) beriman dan bertakwa kepada Tuhan Yang Maha Esa dan menghayati falsafah bangsa, (2) berbudi pekerti luhur, berdisiplin dalam masyarakat, berbangsa dan benegara, (3) bersikap rasional, dinamis dan sadar akan hak dan kewajiban sebagai warganegara, (4) bersifat profesional yang dijiwai oleh kesadaran bela negara, dan (5) aktif memanfaatkan ilmu pengetahuan dan teknologi serta seni untuk kepentingan kemanusiaan, bangsa dan negara.

\section{Klarifikasi Nilai}

Values Clarification Technique (VCT) yaitu proses penerjemahan, penjelasan tentang nilai melalui refleksi dan lain-lain. Klarifikasi nilai merupakan model pembelajaran yang memberikan kebebasan anak untuk menunjukkan kepentingan dirinya, tujuan dan aspirasinya, keyakinan dan sikapnya dan indikator lain yang terkait dengan nilai. Hall (Sutarjo:78) mengartikan teknik klarifikasi nilai (VCT) sebagai:

"By value clarification we mean a methodology or process by which we help a person to discover values through behavior, feelings, ideas, and through important choises he has made and is continually, in fact, acting upon in and through his life".

Menurut Hall, VCT adalah metode klafirikasi nilai, di mana peserta didik tidak disuruh menghafal dan tidak “disuapi” dengan nilai-nilai yang sudah dipilihkan pihak lain, melainkan dibantu untuk menemukan, menganalisis, mempertanggungjawabkan, mengembangkan, memilih, mengambil sikap dan mengamalkan nilai-nilai hidupnya sendiri. Dengan demikian, penggunaan metode klarifikasi nilai ini akan membantu siswa untuk mengambil keputusan 
sendiri, mengarahkan kehidupannya sendiri, tanpa campur tangan yang tidak perlu dari pihak lain.

Klarifikasi nilai adalah metode yang membantu siswa untuk memahami dan memilih nilai yang mereka yakini. Klarifikasi nilai merupakan salah satu metode yang berupaya menumbuhkan kecerdasan intelektual anak didik agar mampu melahirkan suatu keputusan moral yang terbaik dan penuh rasa tanggung jawab. Metode ini, mengajarkan siswa untuk mengatasi masalah, sekalipun dalam situasi nilai moral yang sangat dilematis dan problematika.

Adapun langkah-langkah pembelajaran values clarification technique menurut John Jerolemik (Wina Sanjaya, 2008: 284) membagi ke dalam 3 tingkat:

1). Kebebasan memilih, terdiri tiga tahap yaitu:

a).Memilih secara bebas, artinya kesempatan untuk menentukan pilihan yang menurutnya baik.

b).Memilih dari berbagai alternative, artinya untuk menentukan pilihan dari beberapa alternative pilihan secara bebas.

c).Memilih setelah dilakukan analisis pertimbangan konsekuensi yang akan timbul sebagai akibat pilihannya.

2). Menghargai, terdiri dari dua tahap yaitu:

a).Adanya perasaan senang dan bangga dengan nilai yang menjadi pilihannya.

b).Menegaskan nilai yang sudah menjadi bagian integral dalam dirinya di depan umum.

3). Berbuat, terdiri dari dua tahap yaitu:

a).Kemauan dan kemampuan untuk mencoba melaksanakannya. 
b).Mengulangi perilaku sesuai dengan nilai pilihannya, artinya nilai yang menjadi pilihannya harus tercermin dalam kehidupan sehari-hari.

Values clarification technique menekankan bagaimana sebenarnya seseorang membangun nilai yang menurut anggapannya baik, yang nantinya nilai-nilai tersebut tercermin dalam perilaku dalam kehidupan di masyarakat.

Menurut Harmin, dkk dalam Sinurat (2004: 139) penerapan klarifikasi nilai akan efektif apabila guru sebagai fasilitator bersikap menerima dan tidak mengadili pilihan nilai dari siswa, dialog yang dibangun secara terbuka, bebas dan individual, guru juga harus menghargai kesediaan siswa untuk ikut berpartisipasi atau tidak, sebaiknya guru menghindari unsur pemaksaan untuk berpendapat dan bersikap. Kemudian guru mampu mendorong siswa untuk menjawab, mengutarakan pilihan dan mengambil sikap secara jujur serta guru harus menghargai respon siswa. Dengan langkahlangkah yang diterapkan oleh guru, model values clarification technique dalam proses pembelajaran dapat bermanfaat bagi penanaman nilai-nilai dan perkembangan sikap serta perilaku siswa.

Selain itu, Wina Sanjaya (2008: 283) menjelaskan values clarification sebagai model dalam strategi pembelajaran nilai mempunyai tujuan:

1). Untuk mengukur atau mengetahui tingkat kesadaran siswa tentang suatu nilai.

2). Membina kesadaran siswa tentang nilai-nilai yang dimiliki baik positif maupun negatif untuk kemudian dibina kearah perbaikan dan peningkatan nilai. 
3). Untuk menanamkan nilai-nilai tertentu pada siswa melalui cara yang rasional dan dapat diterima siswa sehingga pada akhirnya nilai tersebut akan menjadi milik siswa.

4). Melatih siswa bagaimana cara menilai, menerima serta mengambil keputusan terhadap sesuatu persoalan dalam kehidupan sehari-hari.

Dari penjelasan di atas, apabila teknik klarifikasi nilai diterapkan maka bertujuan untuk meningkatkan kemampuan siswa untuk (1) memilih, memutuskan, mengkomunikasikan, mengungkapkan gagasan, keyakinan, nilai-nilai dan perasaannya; (2) berempati atau memahami perasaan orang lain dan melihat sudut pandang orang lain; (3) memecahkan masalah; (4) menyatakan sikap setuju atau tidak setuju, menolak atau menerima pendapat orang lain; (5) mempunyai pendirian dalam mengambil keputusan, menginternalisasikan dan bertingkah laku sesuai dengan nilai yang telah dipilih dan diyakini. Jadi, kesimpulannya adalah values clarification technique dapat melatih siswa untuk berproses melakukan penilaian terhadap nilai-nilai kehidupan yang ada dalam masyarakat dan dapat menetapkan nilai-nilai yang menjadi acuan hidupnya.

\section{Metode Penelitian}

Jenis penelitian yang digunakan dalam penelitian ini adalah penelitian Eksperimen. Penelitian eksperimental (experimental rasearch), yang bertujuan untuk meneliti pengaruh dari suatu perlakuan tertentu terhadap gejala suatu kelompok lain yang sama tetapi diberi perlakuan yang berbeda. Penelitian eksperimental dilakukan pada kelas yang akan dilakukan perlakuan (treatment) atau yang disebut kelas eksperimen (experimental group) dan kelas pembanding yang disebut dengan 
Ari Wibowo

kelompok kontrol (control group). Desain penelitian eksperimen yang digunakan adalah two group pre test post test design.

Populasi dan sampel penelitian ini adalah siswa kelas XI di SMA Laboratorium School Universitas Kristen Satya Wacana Salatiga. Sedangkan teknik pengumpulan datanya menggunakan teknik non tes. Teknik non tes yang digunakan dalam penelitian ini adalah melalui angket dan observasi. Angket adalah sejumlah pertanyaan tertulis yang menggunakan informasi dari responden dalam arti laporan tentang pribadinya, atau hal-hal yang diketahui. Angket dalam penelitian ini adalah jenis angket tertutup dengan menggunakan skala likert. Dalam kuesioner, pertanyaan yang disampaikan adalah untuk memperoleh informasi karakter siswa setelah mengikuti pembelajaran menggunakan metode klarifikasi nilai dalam pelajaran PKn.

\section{Hasil Penelitian}

Berdasarkan hasil analisis diskriptif (data pretest dan posttest), nilai karakter baik pada kelas eksperimen maupun pada kelas kontrol menunjukan adanya perbedaan. Hasil pretest kelas eksperimen (yang belajar dengan menggunakan metode klarifikasi nilai) menunjukan bahwa nilai rerata (mean) karakter siswa adalah 88,16 , sedangkan untuk kelas kontrol (yang belajar menggunakan metode konvensional) menunjukan bahwa nilai rerata (mean) karakter siswa adalah 87,09. Sedangkan untuk hasil posttest kelas eksperimen (yang belajar dengan menggunakan metode klarifikasi nilai) menunjukan bahwa rerata (mean) karakter adalah 120,63, dan untuk kelas kontrol (yang belajar menggukanan metode konvensional) menunjukan bahwa nilai rerata (mean) karakter adalah 109, 16. 
Tabel 1. Peningkatan Skor Rerata Peningkatan Aspek Karakter Siswa

\begin{tabular}{|c|c|c|c|c|}
\hline \multirow{2}{*}{$\begin{array}{c}\text { Peningkatan Aspek } \\
\text { Karakter }\end{array}$} & \multicolumn{2}{|c|}{ Kelas Eksperimen } & \multicolumn{2}{|c|}{ Kelas Kontrol } \\
\hline & Rerata & Persentase & Rerata & Persentase \\
\hline Skor Awal & & & & \\
\hline Kreativitas & 23.37 & & 22.16 & \\
\hline Skor Akhir & & & & \\
\hline Kreativitas & 31.57 & & 28.78 & \\
\hline Peningkatan & 8.2 & 35.09 & 6.63 & 29.92 \\
\hline Skor Awal Tanggung & & & & \\
\hline Jawab & 23.37 & & 22.06 & \\
\hline Skor Akhir & & & & \\
\hline Tanggung Jawab & 32.27 & & 28.28 & \\
\hline Peningkatan & 8.9 & 38.08 & 6.22 & 28.20 \\
\hline Skor Awal & & & & \\
\hline Kemandirian & 20.77 & & 20.72 & \\
\hline Skor Akhir & & & & \\
\hline Kemandirian & 28.27 & & 25.25 & \\
\hline Peningkatan & 7.5 & 36.11 & 4.53 & 21.86 \\
\hline Skor Awal Empati & 20.67 & & 22.16 & \\
\hline Skor Akhir Empati & 28.53 & & 26.84 & \\
\hline Peningkatan & 7.83 & 37.88 & 4.67 & 21.07 \\
\hline
\end{tabular}

Bila dilihat dari besarnya nilai rerata data pretest dan posttest hasil belajar dan karakter, maka dapat disimpulkan bahwa ada peningkatan rerata skor untuk kedua nilai tersebut, kelas eksperimen lebih besar daripada peningkatan yang terjadi pada kelas kontrol. Hal ini berarti pengggunaan metrode klarifikasi nilai lebih efektif daripada menggunakan metode konvensional.

Hasil dari analisis diskriptif lebih diperjelas lagi dengan hasil pengujian hipotesis. Hasil pengujian hipotesis pertama diperoleh $t_{\text {hitung }}=6,308$. Pada taraf signifikansi 0,05 dan $\mathrm{df}=60$, diperoleh 
nilai $t_{\text {tabel }}=2,000$. Berarti $t_{\text {hitung }}>t_{\text {tabel }}(6,308>2,000)$. Dengan demikian menunjukan adanya perbedaan hasil belajar hasil metode klarifikasi nilai dengan metode konvensional. Hasil penelitian ini sejalan dengan penelitian Ajat Sudrajat (2011) yang menyimpulkan bahwa metode VCT merupakan salah satu metode yang cocok untuk meningkatkan sikap, nilai, dan kemandirian mahasiswa. Kecocokan ini didasarkan pada tekniknya yang melibatkan diri mahasiswa dalam menentukan nilai-nilai yang akan diputuskan. Dengan demikian metode klarifikasi nilai sejalan dengan pendidikan karakter yang berupaya penanaman kecerdasan dalam berpikir, penghayatan dalam bentuk sikap, dan pengalaman dalam bentuk perilaku sesuai dengan nilai-nilai luhur yang menjadi jati dirinya.

\section{Simpulan}

Penelitian ini membuktikan bahwa metode klarifikasi nilai merupakan metode pembelajaran yang dapat mengimplikasikan perubahan-perubahan dalam kognisi melalui pengetahuan dan informasi, dan ketampilan baru, serta perubahan dalam segi afektif yang berhubungan dengan perasaan, sikap, dan emosi. Metode klarifikasi nilai membantu peserta didik untuk berubah, sehingga mereka bertindak dengan cara yang lebih dapat diterima, baik secara personal maupun sosial. Hasil pengujian hipotesis pertama diperoleh $t_{\text {hitung }}=6,308$. Pada taraf signifikansi 0,05 dan $\mathrm{df}=60$, diperoleh nilai $t_{\text {tabel }}=2,000$. Berarti $t_{\text {hitung }}>t_{\text {tabel }}(6,308>$ 2,000). Dengan demikian menunjukan adanya perbedaan hasil belajar hasil metode klarifikasi nilai dengan metode konvensional.

\section{Saran}

1. Guru perlu mempelajari dengan baik dan benar tentang konsep pembelajaran dengan menerapkan teknik klarifikasi nilai. 
2. Guru sebaiknya memahami metode yang digunakan untuk mengintegrasikan nilai karakter siswa dalam pembelajaran.

3. Guru sebaiknya memahami secara mendalam kondisi siswa, materi, tujuan belajar, sehingga dapat mengaitkan dan memprioritaskan nilai-nilai karakter yang hendak diintegrasikan.

4. Perlu adanya kesamaan visi dan misi dari semua warga sekolah untuk komitmen mendukung pendidikan budi pekerti di sekolah.

\section{Daftar Pustaka}

Amril M. (2006). Implementasi Klarifikasi Nilai dalam Pembelajaran dan Fungsionalisasi Etika Islam. Jurnal Ilmiah Keislaman. Vol. 5 No. 1, 32-50

Ajat Sudrajat. (2011). Mewujudkan Insan Cendikia, Mandiri dan Bernurani melalui Metode Values Clarification Technique (VCT) dalam Mata Kuliah Sejarah Lokal Jurusan Pendidikan Sejarah FISE UNY. SOCIA No. 1 vol 10 edisi Mei 2011.

Berkowitz, M.W. \& Bier, M.C. (2005). What Works In Character Education: A research-driven guide for educators. Washington, DC : Character Education Partnership. Diambil pada $13 \quad$ Oktober 2012, dari http://mindoh.org/docs/WWCE_Practitioner.pdf

Borba, M. (2008). Membangun Kecerdasan Moral. (Terjemahan Lina Jusuf). Jakarta: Gramedia Pustaka Utama.

Bunyamin Maftuh. (2008). Internalisasi Nilai-Nilai Pancasila dan Nasionalisme Melalui Pendidikan Kewarganegaraan. Educationist Vol. 2 No. 2, 60-78.

Darmiyati Yuchdi. (2008). Humanisme Pendidikan. Jakarta: Bumi Aksara. 
Dimerman, S. (2009). Character is The Key. Mississauga : John Weley \& Sons Canada Ltd.

Doni Koesoema (2007). Pendidikan Karakter, Strategi Mendidik Anak di Zaman Global. Jakarta: Gramedia Widiasarana Indonesia.

Eggel S. \& Randall, K. (2009) How Theacher Respond to Children's Inquiry. American Educational Research Journal. Vol. 46 No.1

Easterbrooks, S. R. \& Scheetz N.A. (2004). Applying Critical Thinking Skills to Character Education and Values Clarification With Students Who Are Deaf or Hard of Hearing. American Annals of the Deaf,149, 255-26.

Eni, Purwandari \& Purwati. (2008). Character Building :Pengaruh Pendidikan Nilai Terhadap Kecerdasan Anak. Jurnal Penelitian Humaniora Vol. 9 No. 1, Februari 2008.

Frankel, J. R. (1977). How to Teach About Values, an Analytic Approach. London: Prentice-Hall, Inc.

Gagne, R. M. \& Brigs, L. J. (1979). Principles of Instructional design. Second edition. United States of America. Holt Rinehart and Winston.

Goleman, D. (2002). Emotional Intelegence : Kecerdasan Emosional, (Terjemahan T. Hermaya) Jakarta : Gramedia Pustaka Utama.

H.A.R., Tilaar. (2004). Multikulturalisme Tantangan-tantangan Global Masa Depan dalam Tranformasi Pendidikan Nasional. Jakarta: Grasindo.

Ine K.A. \& Markum S. (2010). Pendidikan Kewarganegaraan Berbasis Nilai. Bogor: Ghalia Indonesia.

Kessler, R. (2000). The Soul of Education. USA: Association for Supervision and Curriculum Development.

Kokom Komalasari. (2012). The Living Values-Based Contextual Learning to Develop the Students' Character. Journal of Social Sciences 8 (2): 246-251.

Kirschenbaum, H. (2000). From Values Clarification to Character Education: A Personal Journey. Journal of Humanistic 
Counseling, Education \& Development, 39(1), 4-20. Retrieved from EBSCOhost.

Lickona, T. (1991). Educating fot Character. How Our Schools can Theach Respect and Responsibility. New York: Batam Books.

Book.

Mawardi Lubis. (2001). Evaluasi Pendidikan Nilai. Yogyakarta: Pustaka Pelajar.

Mohammad Noor Syam. (1983). Filsafat Pendidikan dan Dasar Filsafat Pendidikan Pancasila. Surabaya: Usaha Nasional.

Nurul Suria. (2008). Pendidikan Moral \& Budi Pekerti dalam Perspektif Perubahan. Jakarta: Bumi Aksara.

Raths, L. E., Merrill H. \& Sidney B. S. (1966) Values and Teaching: Working with Values in the Classroom. Columbus, Ohio : Charles E. Marrill Publishing Co.

Simon, S. B. (1972).Values Clarification. New York : Hart Publishing Company.

Stevenson, N. (2006). Young Person's Character Education Handbook. USA:JIST life.

Sugirin. (2010). Affective Domain Development: Reality and Expectation. Cakrawala Pendidikan. Th. XXIX No. 3, November 2010.

Sukardi. (2005). Metodologi Penelitian Pendidikan: Kompetensi dan Prakteknya. Jakarta: Bumi Aksara.

Tadkiroatun Musfiroh. (2008). Pengembangan Karakter Anak Melalui Pendidikan Karakter Dalam Tinjauan Berbacai Aspek, Character Building, Yogyakarta: lembaga pelitian UNY.

Tillman Diane. (2004). Living Values activities for children ages 814. Jakarta: Gramedia Widiasarana Indonesia.

Zamroni. (2001). Pendidikan untuk Demokrasi. Yogyakarta: Bigraf Publishing. 